\title{
Cognitive and Social Sources of Adolescent Well-being: Mediating Role of School Belonging
}

\author{
Gabriela Šeboková, Jana Uhláriková, Mária Halamová \\ Constantine the Philosopher University, Nitra, Slovak Republic
}

\begin{abstract}
The aim of the study was to explore direct and indirect pathways from cognitive factors (academic and social self-perception) to adolescent well-being through school belonging. The direct and indirect effects of cognitive factors were investigated on both concurrent and prospective well-being indicators. The first data collection was held in the beginning of the school year, the study sample consisted of 139 freshmen of three high schools in Nitra (53 boys, 86 girls, $\left.M_{\text {age }}=15.63, S D=1.15\right)$. The second data collection was held six months later from 109 respondents (40 boys, 69 girls, $M_{\text {age }}=15.16$ ). Self-report questionnaires were utilized. Results showed that school belonging mediated the association between social and academic competence and students' concurrent optimism, connectedness and happiness. School belonging also mediated the relationship of social competence to prospective optimism, connectedness and happiness. Findings suggest that a developed sense of connection to school in the transition period may promote overall well-being in adolescents.
\end{abstract}

Key words: self-competence, school belonging, well-being, mediation analysis

Studying well-being, defined as positive characteristics and indicators of satisfied and happy life, is a topic of great theoretical and practical significance. However, examining well-being in youths has lagged behind the studies of adults. Adolescents spend a considerable amount of time at school. Hence, it is not surprising that school experience plays an important role in their health and successful lifelong development (Jose, Ryan, \& Pryor, 2012; Phan, Ngum, \& Alrashidi, 2016). Particularly, the period of school transitions holds considerable importance, as

Acknowledgements: The article was written within the scope of the grant agency VEGA 1/0577/16 Personal and interpersonal factors of adaptive development in the context of school environment. Correspondence concerning this article should be addressed to Gabriela Šeboková, Department of Psychological Sciences, Constantine the Philosopher University in Nitra, Kraskova 1, 94974 Nitra, Slovak Republic. E-mail: gabriela.sebokova@gmail.com

Received July 11, 2017 it is when parallel changes in social and cognitive factors of adolescent functioning occur (Lester, Waters, \& Cross, 2013). In the past years, there have been calls for schools to expand the aims of education beyond learning outcomes to promote well-being (Gajdošová, 2016). In the present study, we explore the role of both cognitive and social resources of adolescent school life after the transition, in promoting concurrent and prospective positive psychological functioning, examined via the EPOCH model of subjective well-being. We investigate whether the effect of cognitive factors (self-perception) on adolescents' well-being is mediated by social domain (school belonging).

Subjective well-being is a meta-construct, consisting of not only the absence of psychological symptoms and disorders but also of the presence of positive feelings, thoughts and behavior (Kern, Benson, Steinberg, \& Steinberg, 2016; Seligman, 2014). In recent years, conceptualization of subjective well-be- 
ing has expanded beyond feeling happy to broader concepts of psychological, personal, cognitive and motivational attributes that define optimal human functioning. Numerous models have been suggested, for example Ryff's theory of Psychological well-being (1989), Antonovsky's Salutogenic theory (1993), Selfdetermination theory (Deci \& Ryan 2000) or in positive psychology Seligman's (2014) multidimensional model of well-being called PERMA.

Based on Seligman's theoretical perspective, Kern et al. (2016) introduced a theoretical and psychometrical model of optimal functioning in adolescents. The model called EPOCH describes five positive characteristics (engagement, perseverance, optimism, connectedness, happiness), which, according to the authors, support flourishing in adulthood. Engagement is described as a capacity to be immersed in and focused on one's activity and involvement and interest in life tasks. Perseverance is defined as a capacity to achieve one's goals regardless of difficulties or obstacles. Optimism is understood as a perception of the future as bright and favorable, being hopeful and confident. An optimistic person considers negative events as temporary, external and specific to a situation. Connectedness represents one's belief that he/she is loved, cared for, valued, supported, while also providing love, support, and care for others. Finally, happiness refers to stable states of positive mood and emotions regarding one's life. All of the five dimensions are non-developmental (normative immaturity does not lead to lower levels of well-being) and not specified in particular context. The EPOCH model represents the general capacity of youth to be engaged, perseverant, optimistic, connected and happy, regardless of the context specificity.

Well-being in adolescents is understood as a multi-dimensional and multi-causal phenomenon, influenced by both individual and contextual variables (Danielsen, Samdal, Hetland,
\& Wold, 2009; Rodriguez-Fernandez et al., 2016; Ronen, Hamama, Rosenbaum, \& MishleyYarlap, 2014). Therefore, a good way to study adolescent positive functioning is to take into account multiple predictors, multiple pathways and multiple well-being outcomes (Friedman \& Kern, 2010). Moreover, recent research has suggested that there are not only direct but also indirect (mediated) pathways from predictors to well-being (Blatný \& Šolcová, 2016). However, most research has focused on the mediating role of cognitive factors (Danielsen et al., 2009; Rodriguez-Fernandez et al., 2016), whereas social factors as potential mediators of the influence of cognitive factors on positive functioning have not been given significant attention. This is why we find it necessary to explore whether cognitive factors directly predict various indicators of adolescent well-being and whether the effect of cognitive factors is (fully or partially) explained via social variables.

The direct effect of cognitive factors (such as self-efficacy, expectancy, effort) on well-being is well documented. In the present study, we focused on one of the cognitive factors self-concept, that we defined as a multifaceted phenomenon composed of various aspects, roles, perspectives or selves. Multidimensional approach of the self assesses how people evaluate their competence, adequacy and knowledge they have in various domains of their lives (Harter, 2012). In the school life of adolescents, scholastic learning and social interactions represent two main activities. Accordingly, the present study focuses on self-perception of academic and social competencies. Academic competence refers to adolescent perception of cognitive competence applied to schoolwork (e.g., perception how well one is doing at schoolwork, at figuring out the answers, perception of one's intelligence). Social competence is described as one's perception of knowing how to make friends, how to become popular, having skills to get others to like oneself. 
According to Harter (2012), domain specific self-perceptions have their unique and separate relations to various indicators of well-being. As previous research suggested, perception of academic competence is more predictive of academic related indicators of well-being, such as persistence, optimism or academic engagement (Phan et al., 2016; Prokopčáková, 2015; Mih \& Mih, 2013), whereas perception of social competence more strongly contributes to non-academic indicators of well-being, such as life satisfaction, quality of life and positive relations with others (Danielsen et al., 2009; Phan et al., 2016; Rodriguez-Fernandez et al., 2016). According to Olsson, McGee, Nada-Raja, \& Williams (2013) social and academic aspects of adolescent development are two important but different pathways to well-being in adulthood.

Indirect effects of cognitive dimensions on well-being through social factors have not been frequently studied. Few studies have suggested that positive self-perception may be indicative of greater engagement of adolescents at school, which in turn may lead to students' positive outcomes (Mih \& Mih, 2013; Phan et al., 2016). It follows that students' positive feelings, experiences and relationships within the school (emotional engagement) may serve as a mediator of the effect of students' individual cognitive factors on optimal functioning.

In the present study we posit school belonging (conceptualized as a factor of emotional engagement) as a central mediator of the relation between self-perception and adolescent well-being. School belonging is defined as "the extent to which students feel personally accepted, respected, included and supported by others in the school social environment" (Goodenow, 1983) and its importance in adolescent development is explained through Maslow hierarchy of needs (1968), Stage-environment fit theory (Eccles et al., 1993) and Self-determination theory (Deci \& Ryan, 2000).
We built our theoretical model on the empirical support suggesting that cognitive factors (such as self-competence, self-esteem, self-efficacy) are significant sources of students' sense of school belonging (Allen, Kern, VellaBrodrick, Hattie, \& Waters., 2016; Pittman \& Richmond, 2007; Vaz et al., 2015), which in turn is concurrently and also longitudinally associated with adolescent behavioral, emotional, social and academic outcomes (Pittman \& Richmond, 2007; O’Neel \& Fuligni, 2013; Pečjak \& Pirc, 2017; Jose et al., 2012; Lester et al., 2013). The theoretical foundation of the mediational model can be found in the Expectancy-value theory (Eccles \& Wigfield, 1995), according to which individual's expectation for success (perceived competence) influences school engagement, which in turn predicts important outcomes in adolescents. Nevertheless, research simultaneously analyzing multiple domains of self-perception and school belonging in relation to various well-being indicators in noneducational settings is limited.

Considering the growing consensus on the conceptualization of well-being as a multi-dimensional and multi-causal phenomenon and the need to study complex relational patterns between its predictors, we explore both direct and indirect pathways from cognitive factors (self-perception) through social factors (school belonging) to multiple indicators of adolescent well-being (engagement, perseverance, optimism, connectedness, happiness). Taking into account different pathways of multiple predictors leading to adolescent well-being, we focus on both academic and social self-perception and investigate their potentially different contributions to various aspects of adolescent wellbeing. Filling the gap in previous research, the aim of the study was to test whether the effect of perceived self-competence on context unspecified indicators of well-being can be mediated by social factors of adolescents school life (school belonging). 
Empirical findings also determined longitudinal associations between cognitive and social variables and adolescent well-being, suggesting their different predictive effect on later wellbeing (Jose et al., 2012; Olsson et al., 2013). Considering these findings, the second aim of the study was to test whether self-perception directly or indirectly (through school belonging) predicts later well-being (six months later).

Present research focused on the sample of high school freshmen shortly after the school transition. Studying students' self-perception and school belonging shortly after a transition has a particular meaning, as school transitions have significant effect on psychological, social and cognitive functioning of adolescents (Harter, 2012). Longitudinal studies suggest that the level of connection to school during the transition period strongly predicts students' later emotional health and academic values (Lester et al., 2013; O’Neel \& Fuligni, 2013). Hence, in the present study we specifically aim to identify crucial factors acting during the period of students' transition, which can promote adolescent concurrent and prospective wellbeing.

\section{Method}

\section{Sample and Procedure}

The first data collection started in the beginning of the school year (during October and November 2016) among students attending three high schools in Nitra. The initial sample consisted of 176 students, attending first, second and fourth year of the study. In order to elaborately examine the effect of transition, we decided to include only freshmen in our sample. The final sample consisted of 139 freshmen, 53 boys $(38.1 \%)$ and 86 girls $(61.9 \%)$ with mean age $15.16(S D=0.49)$. After approval of the survey by the school principals, questionnaires were administered to students during one class period (45 minutes). At the beginning, participants were met by researchers who briefly acquainted them with the purpose of the study and accustomed them to research context. The questionnaires were completed on a voluntary and anonymous basis. Respondents completed all the questionnaires included in the study.

The second data collection was held six months later in April 2017. Sample consisted of 109 respondents ( 40 boys and 69 girls, $M_{\text {age }}=$ 15.16) who completed the EPOCH questionnaire. 19 freshmen from the first data collection did not participate in the second data collection because of an absence during the testing day and 11 students were lost to follow-up.

\section{Materials}

Self-perception profile for adolescents (Harter, 2012) - measures the global self-esteem and competence in eight specific domains of adolescent's life. In the present research two subscales - academic and social competence were used. Each of the scales consists of five statements that are formulated in a "structured alternative format" and individual chooses from two alternative statements (e.g., "Some teenagers do very well at their classwork or Other teenagers don't do well at their classwork") and then rates if the statement is "Really true for me" or "Sort of true for me". The authors of the original questionnaire confirmed good internal consistency $(\alpha=.85-.91)$. Self-perception profile for children (in which social and academic competence scales are identical with the adolescent version) was validated in the Slovak context, documenting satisfactory validity and reliability (Babinčák, Mikulášková, \& Kovalčíková, 2012). In the present study, internal consistency of academic competence scale was $\alpha=.70$, for social competence $\alpha=.83$.

School belonging - questionnaire is a part of the Student questionnaire developed by OECD and utilized in international testing PISA 
(2003). The questionnaire consists of six statements (e.g., "I feel like I belong at school"). Students are asked to indicate how they feel about each item using a four-point scale from "strongly disagree" to "strongly agree". The questionnaire displayed satisfactory level of reliability, validity and cross-cultural applicability (OECD, PISA, 2003). In the present study, internal consistency of the scale was $\alpha=.83$.

EPOCH (Kern et al., 2016) - measures five dimensions of adolescent well-being (engagement, perseverance, optimism, connectedness, happiness). The questionnaire consists of 20 items -4 items for each dimension (e.g., $E$ : "I get completely absorbed in what I am doing" $P$ : "I finish whatever I begin", $O$ : "In uncertain times, I expect the best", $C$ : "There are people in my life who really care about me", $H$ : "I have a lot of fun"). Items are rated on a 5point scale ranging from 1 (almost never) to 5 (almost always). The authors documented high internal consistency $(\alpha=.77-.83)$ and testretest reliability $(r=.37-.49)$ of the scale among adolescents from USA and Australia. Convergent and divergent validity of the scale was supported by correlations with similar and dissimilar constructs. The questionnaire was translated into Slovak by two independent translators, following back translation. Confirmatory factor analysis supported five-factor solution of the Slovak version of EPOCH $\left(\chi^{2}(160)=\right.$ $229.388, p<.001$; $\mathrm{GFI}=.87, \mathrm{CFI}=.93, \mathrm{RMSEA}=$ $.06, \mathrm{CI} 90 \%[.039, .072], \mathrm{SRMR}=.066)$. In the present study, internal consistency of the EPOCH subscales ranged between $\alpha=.73-.86$ at $\mathrm{T} 1$ and between $\alpha=.69-.87$ at $\mathrm{T} 2$.

\section{Results}

\section{Preliminary Analyses}

Prior to analysis, all the variables were checked for missing data. Since the pattern of missing values across variables was random and did not exceed $5 \%$, cases with missing data were replaced with mean of the given variable (Tabachnik \& Fidel, 2001). There were no significant differences in the results of the analysis, when comparing deleting missing cases and imputation of mean values for missing data.

Firstly, the normality of distribution of all variables was calculated. Values of skewness and kurtosis were converted to $z$-scores. School belonging and connectedness were negatively skewed, however, considering the large sample size, we utilized parametric statistics (Tabachnik \& Fidel, 2001). Bivariate correlations were calculated to display interrelationships among predictors, mediator and outcome variables and to test the presence of multicollinearity. None of the correlation coefficients exceeded .90 , which confirmed that multicollinearity among study variables was not severe. The results of correlation and descriptive analysis are presented in Table 1. Academic and social competence scales displayed significant positive correlations with well-being indicators (first testing - T1) and school belonging, social competence having stronger associations. School belonging showed significant strong positive correlations with well-being (T1), except for a small correlation with engagement and perseverance scales. There were no significant correlations between engagement and perseverance scales at second testing (T2) with perceived competence and school belonging. Optimism, connectedness and happiness at $\mathrm{T} 2$ showed significant positive, moderate to strong correlations with social competence and school belonging. The strength of correlation was interpreted in line with Cohen's (1992) recommendation.

To determine gender differences in the study variables, independent samples $t$-tests were calculated. Boys reported higher levels of academic competence than girls $(t(137)=2.97, p=$ $.004, d=0.52)$, whereas girls reported higher level of connectedness $(t(137)=-2.16, p=.003$, $d=0.37$ ) than boys did. The effect size of differ- 
Table 1 Descriptive characteristics, reliability and correlations among study variables in sample (T1) $N=139$, T2 in sample $n=109$

\begin{tabular}{lcccccccccccccc}
\hline & $M(S D)$ & $\alpha$ & 1 & 2 & 3 & 4 & 5 & 6 & 7 & 8 & 9 & 10 & 11 & 12 \\
\hline 1. AC & $13.37(2.93)$ & .70 & - & & & & & & & & & & \\
2. SC & $13.91(3.31)$ & .83 & $.36^{* *}$ & - & & & & & & & & & \\
3. SB & $19.37(3.01)$ & .83 & $.39^{* *}$ & $.73^{* *}$ & - & & & & & & & & \\
4. ET1 & $12.82(3.11)$ & .76 & $.28^{* *}$ & $.26^{* *}$ & $.22^{* *}$ & - & & & & & & & \\
5. PT1 & $13.40(3.13)$ & .73 & $.27^{* *}$ & $.20^{* *}$ & $.27^{* *}$ & $.46^{* *}$ & - & & & & & & \\
6. OT1 & $13.50(3.52)$ & .77 & $.40^{* *}$ & $.53^{* *}$ & $.59^{* *}$ & $.32^{* *}$ & $.34^{* *}$ & - & & & & & \\
7. CT1 & $16.90(3.00)$ & .80 & $.22^{* *}$ & $.50^{* *}$ & $.50^{* *}$ & $.21^{*}$ & $.29^{* *}$ & $.38^{* *}$ & - & & & & \\
8. HT1 & $14.74(3.66)$ & .86 & $.33^{* *}$ & $.64^{* *}$ & $.70^{* *}$ & $.30^{* *}$ & $.27^{* *}$ & $.64^{* *}$ & $.57^{* *}$ & - & & & \\
9. ET2 & $11.81(2.98)$ & .78 & .13 & .12 & .10 & $.51^{* *}$ & $.36^{* *}$ & .14 & $.23^{*}$ & $.20^{*}$ & - & & \\
10. PT2 & $12.97(2.89)$ & .69 & .17 & .11 & .05 & $.28^{* *}$ & $.78^{* *}$ & $.23^{*}$ & $.30^{* *}$ & $.24^{*}$ & $.31^{* *}$ & - & & \\
11. OT2 & $12.67(3.40)$ & .77 & .12 & $.34^{* *}$ & $.36^{* *}$ & .14 & .13 & $.60^{* *}$ & $.42^{* *}$ & $.53^{* *}$ & .15 & .12 & - & \\
12. CT2 & $17.04(3.03)$ & .83 & $.20^{*}$ & $.53^{* *}$ & $.56^{* *}$ & -.02 & .17 & .14 & $.71^{* *}$ & $.34^{* *}$ & -.02 & .05 & $.38^{* *}$ & - \\
13. HT2 & $14.18(3.67)$ & .87 & .19 & $.46^{* *}$ & $.50^{* *}$ & .14 & .14 & $.45^{* *}$ & $.54^{* *}$ & $.74^{* *}$ & $.19^{*}$ & .13 & $.65^{* *}$ & $.53^{* *}$ \\
\hline
\end{tabular}

Note. $\mathrm{AC}=$ academic competence, $\mathrm{SC}=$ social competence, $\mathrm{SB}=$ school belonging, $\mathrm{E}=$ engagement, $\mathrm{P}=$ perseverance, $\mathrm{O}=$ optimism, $\mathrm{C}=$ connectedness, $\mathrm{H}=$ happiness ${ }^{*} p<.05,{ }^{* *} p<.01$

ences was medium and small, respectively (Cohen, 1992). There were no statistically significant gender differences in other tested variables.

\section{Mediation Analyses at T1}

In order to examine the mediating role of school belonging (M) in the relationship between perceived social and academic competence (IV) and indicators of well-being (DV: engagement, perseverance, optimism, connectedness, and happiness), the mediation analysis was performed. Also, multiple regression analysis was utilized (Baron \& Kenny, 1986). Direct (effect of IV on DV controlling for M) and indirect effect (effect of IV on DV through $\mathrm{M}$ ) were calculated using the statistical program called PROCESS developed by Hayes (2013). We tested the significance of the indirect effect using the Sobel test $(Z)$ and bootstrapping procedure. Standardized indirect effect was calculated for each 10000 bootstrapped samples and the $95 \%$ bootstrapped confidence interval was computed. The effect size was calculated as a proportion of variance in dependent variable, explained by the indirect effect $\left(R^{2}{ }_{\text {med }}\right)$ (Hayes, 2013).

Overall, 10 mediational models were tested with well-being indicators as dependent variables at Time 1 . We did not perform mediation analysis for engagement and perseverance at Time 2 and for academic competence (IV) because the correlations between these and other tested variables were too small and non-significant. Three mediational models with well-being indicators as dependent variables at Time 2 were performed. Results of the mediation analysis (unstandardized total, direct and indirect effects with bootstrapped $95 \%$ confidence intervals and effect size) are presented in Table 2. Significant mediational models expressed in standardized regression coefficients with total (c), direct (c') and indirect (ab) effects are presented in Figures 1 to 3.

Results of mediational analysis showed that there is only significant direct effect of academic competence on engagement and perseverance at Time 1. School belonging did not mediate the relationship between academic competence and 
engagement and perseverance, respectively $(Z=1.30, p=.194$, resp. $Z=1.99, p=.051)$. This was also revealed by $95 \%$ bootstrap confidence interval that contained zero or was only slightly above zero. Moreover, $R^{2}$ med indicates that only $3 \% / 4 \%$ of the variance in engagement/perseverance respectively, is attributable to the indirect effect of academic competence through school belonging.

There was a significant indirect effect of academic competence on optimism $(0.24, Z=3.45$, $p<.001)$, connectedness $(0.19, Z=3.30, p=$ $.001)$ and happiness $(0.32, Z=4.25, p<.001)$ at Time 1 , as confirmed also by a $95 \%$ bootstrap confidence interval that was entirely above zero. Given that direct effect of academic competence on optimism after controlling for mediator remained statistically significant, mediating role of school belonging was partial. The $R^{2}$ med indicates that $13 \%$ of the variance in optimism is attributable to the indirect effect of the academic competence through school belonging. The direct effect of academic competence on connectedness and happiness was no longer statistically significant, meaning that school belonging fully mediated the relationship between academic competence and connectedness, and happiness, respectively. The $R^{2}{ }_{\text {med }}$ indicates that $5 \% / 10 \%$ of the variance in connectedness/hap- piness is attributable to the indirect effect of the academic competence through school belonging.

Next, mediational models with social competence as the independent variable were tested. Results showed no direct or indirect effect of social competence on engagement and at Time 1. There was a significant indirect effect of social competence on perseverance $(0.18, Z=2.28$, $p=.023)$. However, $95 \%$ bootstrap confidence interval was only slightly above zero and the $R^{2}$ med indicates that only $4 \%$ of the variance in perseverance is attributable to the indirect effect of the social competence through school belonging. There was a significant indirect effect of social competence on optimism $(0.34$, $Z=4.07, p<.001)$ connectedness $(0.20, Z=2.42$, $p=.016)$ and happiness $(0.40, Z=4.29, p<.001)$ at Time 1 , as revealed also by a $95 \%$ bootstrap confidence interval that was entirely above zero. Given that direct effect of social competence on optimism, connectedness and happiness remained statistically significant, the mediating role of school belonging was in all cases partial. The $R^{2}$ med indicates that $26 \% / 21 \% / 37 \%$ of the variance in optimism/connectedness/happiness, respectively, is attributable to the indirect effect of the social competence through school belonging.

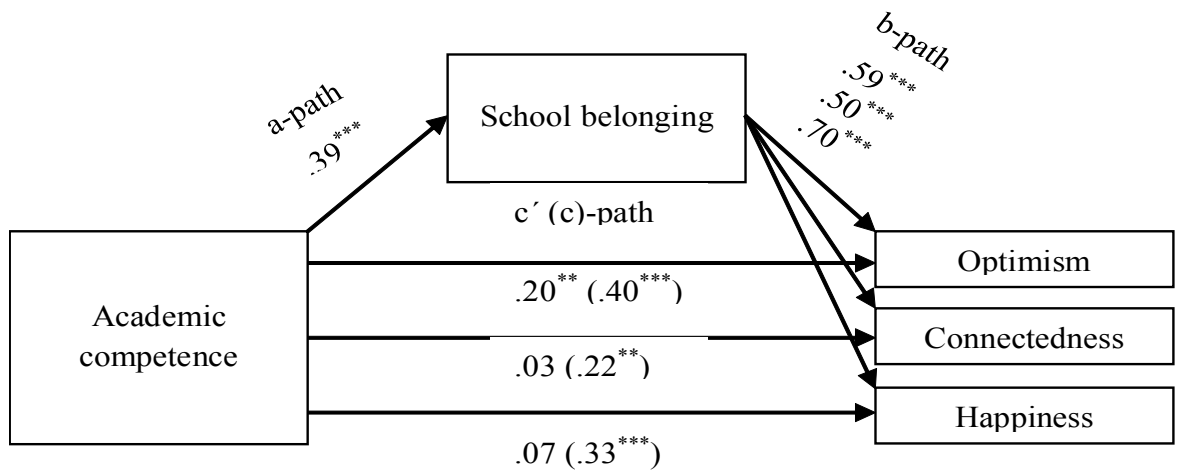

Figure 1 Mediating model of the relationship between academic competence and optimism, connectedness and happiness, respectively, with school belonging as mediator 


\section{Mediation analyses at $\mathrm{T} 2$}

Finally, mediational models with well-being indicators at Time 2 as dependent variables were tested. There was no significant direct or indirect effect of social competence on optimism at Time 2 . However, the $R^{2}$ med indicates that $10 \%$ of the variance in optimism is attributable to the indirect effect of the social competence through school belonging.

There were significant indirect effects of social competence on connectedness $(0.24, Z=$ $3.01, p=.003)$ and happiness $(0.29, Z=2.87, p$ $=.004)$, as revealed also by a $95 \%$ bootstrap confidence interval that was entirely above zero. Given that direct effect of social competence on connectedness remained statistically significant, the mediating role of school belonging was partial. The $R^{2}$ med indicates that $25 \%$ of the variance in connectedness is attributable to the indirect effect of the social competence through school belonging. The direct effect of social competence on happiness was, after controlling for the mediator, no longer statistically significant, meaning that school belonging fully mediated the relationship between social competence and happiness at Time 2. The $R^{2}$ med indicates that $19 \%$ of the variance in happiness is attributable to the indirect effect of the social competence through school belonging.

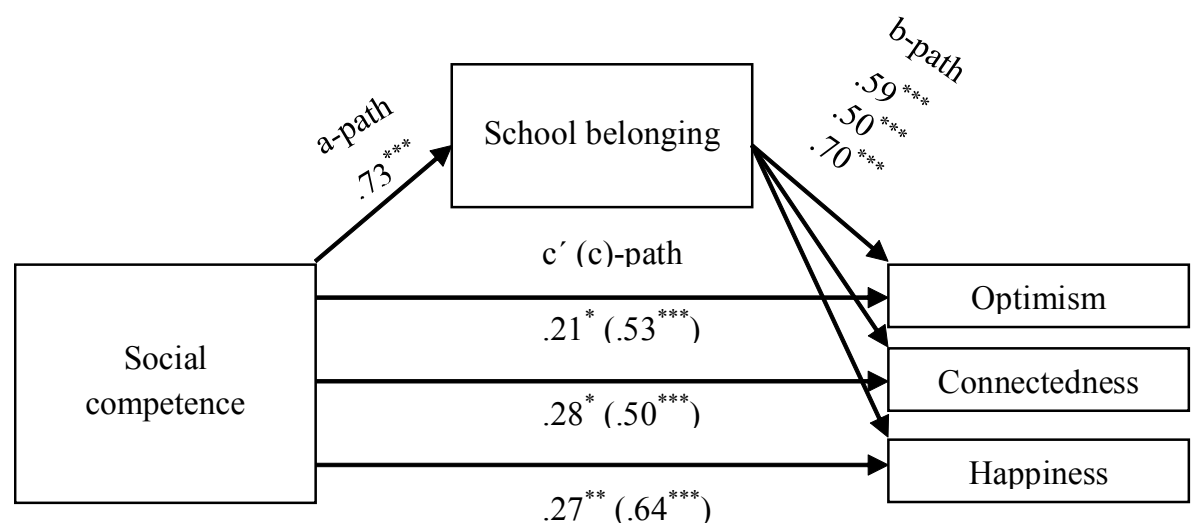

Figure 2 Mediating model of the relationship between social competence and optimism, connectedness and happiness, respectively, with school belonging as mediator

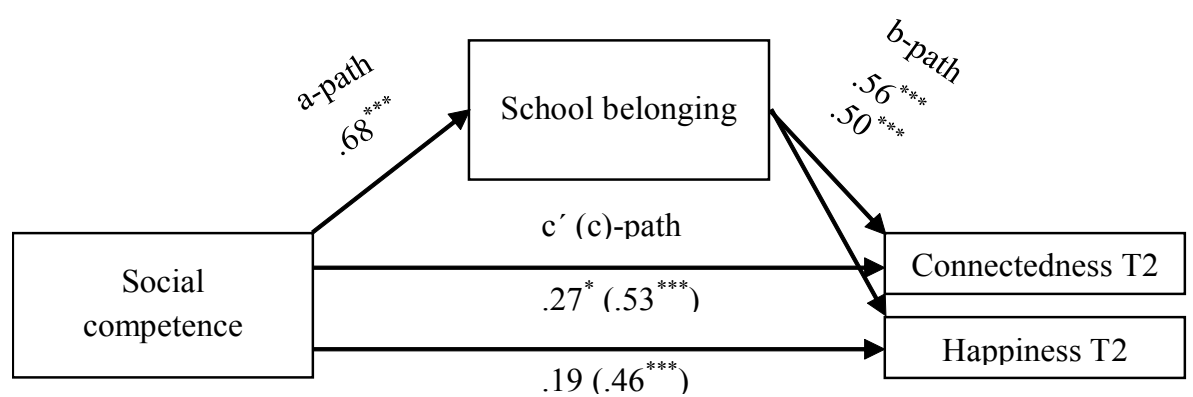

Figure 3 Mediating model of the relationship between social competence and connectedness at Time 2 and happiness at Time 2, respectively, with school belonging as mediator 
Table 2 Unstandardized direct, indirect and total effects of all tested mediational analysis

\begin{tabular}{|c|c|c|c|c|c|}
\hline Predictor & Mediator & Criterion & & $\operatorname{cts}[95 \% \mathrm{CI}]$ & $\begin{array}{c}\text { Effect } \\
\text { size } \\
\mathrm{R}^{2} \text { med }\end{array}$ \\
\hline \multirow{3}{*}{$\begin{array}{l}\text { Academic } \\
\text { competence }\end{array}$} & \multirow{3}{*}{$\begin{array}{l}\text { School } \\
\text { belonging }\end{array}$} & \multirow{3}{*}{ Engagement } & Direct & $0.25^{*}[0.05,0.44]$ & \multirow{3}{*}{.03} \\
\hline & & & Indirect & $0.05[-0.02,0.14]$ & \\
\hline & & & Total & $0.30^{* *}[0.12,0.47]$ & \\
\hline \multirow{3}{*}{$\begin{array}{l}\text { Academic } \\
\text { competence }\end{array}$} & \multirow{3}{*}{$\begin{array}{l}\text { School } \\
\text { belonging }\end{array}$} & \multirow{3}{*}{ Perseverance } & Direct & $0.21^{*}[0.01,0.41]$ & \multirow{3}{*}{.04} \\
\hline & & & Indirect & $0.08[0.01,0.17]$ & \\
\hline & & & Total & $0.29^{* *}[0.11,0.47]$ & \\
\hline \multirow{3}{*}{$\begin{array}{l}\text { Academic } \\
\text { competence }\end{array}$} & \multirow{3}{*}{$\begin{array}{l}\text { School } \\
\text { belonging }\end{array}$} & \multirow{3}{*}{ Optimism } & Direct & $0.24^{*}[0.05,0.43]$ & \multirow{3}{*}{.13} \\
\hline & & & Indirect & $0.24^{* * *}[0.14,0.37]$ & \\
\hline & & & Total & $0.48^{* * *}[0.29,0.67]$ & \\
\hline \multirow{3}{*}{$\begin{array}{l}\text { Academic } \\
\text { competence }\end{array}$} & \multirow{3}{*}{$\begin{array}{l}\text { School } \\
\text { belonging }\end{array}$} & \multirow{3}{*}{ Connectedness } & Direct & $0.03[-0.15,0.21]$ & \multirow{3}{*}{.05} \\
\hline & & & Indirect & $0.19^{* *}[0.10,0.32]$ & \\
\hline & & & Total & $0.23^{*}[0.06,0.40]$ & \\
\hline \multirow{3}{*}{$\begin{array}{l}\text { Academic } \\
\text { competence }\end{array}$} & \multirow{3}{*}{$\begin{array}{l}\text { School } \\
\text { belonging }\end{array}$} & \multirow{3}{*}{ Happiness } & Direct & $0.09[-0.08,0.25]$ & \multirow{3}{*}{.10} \\
\hline & & & Indirect & $0.32^{* * *}[0.19,0.46]$ & \\
\hline & & & Total & $0.41^{* * *}[0.21,0.62]$ & \\
\hline \multirow{3}{*}{$\begin{array}{l}\text { Social } \\
\text { competence }\end{array}$} & \multirow{3}{*}{$\begin{array}{l}\text { School } \\
\text { belonging }\end{array}$} & \multirow{3}{*}{ Engagement } & Direct & $0.20[-0.04,0.45]$ & \multirow{3}{*}{.05} \\
\hline & & & Indirect & $0.04[-0.12,0.24]$ & \\
\hline & & & Total & $0.24^{*}[0.10,0.39]$ & \\
\hline \multirow{3}{*}{$\begin{array}{l}\text { Social } \\
\text { competence }\end{array}$} & \multirow{3}{*}{$\begin{array}{l}\text { School } \\
\text { belonging }\end{array}$} & \multirow{3}{*}{ Perseverance } & Direct & $0.01[-0.22,0.22]$ & \multirow{3}{*}{.04} \\
\hline & & & Indirect & $0.18^{*}[0.04,0.37]$ & \\
\hline & & & Total & $0.19^{*}[0.04,0.34]$ & \\
\hline \multirow{3}{*}{$\begin{array}{l}\text { Social } \\
\text { competence }\end{array}$} & & & Direct & $0.22^{*}[0.04,0.40]$ & \\
\hline & School & Optimism & Indirect & $0.34^{* * *}[0.20,0.52]$ & .26 \\
\hline & & & Total & $0.56^{* * *}[0.39,0.73]$ & \\
\hline & & & Direct & $0.25^{*}[0.05,0.45]$ & \\
\hline Social & School & Connectedness & Indirect & $0.20^{*}[0.06,0.36]$ & .21 \\
\hline & & & Total & $0.45^{* * *}[0.30,0.60]$ & \\
\hline & & & Direct & $0.30^{* *}[0.09,0.52]$ & \\
\hline Social & School & Happiness & Indirect & $0.40^{* * *}[0.22,0.57]$ & .37 \\
\hline & & & Total & $0.70^{* * *}[0.56,0.85]$ & \\
\hline & & & Direct & $0.16[-0.11,0.44]$ & \\
\hline Social & School & OptimismT2 & Indirect & $0.18[-0.03,0.42]$ & .10 \\
\hline & & & Total & $0.35^{* *}[0.12,0.57]$ & \\
\hline
\end{tabular}

Table 2 continues 
Table 2 continued

\begin{tabular}{|c|c|c|c|c|c|}
\hline Predictor & Mediator & Criterion & & $\operatorname{cts}[95 \% \mathrm{CI}]$ & $\begin{array}{l}\text { Effect } \\
\text { size }\end{array}$ \\
\hline \multirow{3}{*}{$\begin{array}{l}\text { Social } \\
\text { competence }\end{array}$} & \multirow{3}{*}{$\begin{array}{l}\text { School } \\
\text { belonging }\end{array}$} & \multirow{3}{*}{ ConnectedT2 } & Direct & $0.24^{*}[0.04,0.45]$ & \multirow{3}{*}{.25} \\
\hline & & & Indirect & $0.24^{* *}[0.07,0.43]$ & \\
\hline & & & Total & $0.49^{* * *}[0.28,0.69]$ & \\
\hline \multirow{3}{*}{$\begin{array}{l}\text { Social } \\
\text { competence }\end{array}$} & \multirow{3}{*}{$\begin{array}{l}\text { School } \\
\text { belonging }\end{array}$} & \multirow{3}{*}{ HappinessT2 } & Direct & $0.21[-0.13,0.55]$ & \multirow{3}{*}{.19} \\
\hline & & & Indirect & $0.29^{* *}[0.07,0.58]$ & \\
\hline & & & Total & $0.50^{* * *}[0.28,0.72]$ & \\
\hline
\end{tabular}

${ }^{*} p<.05,{ }^{* *} p<.01,{ }^{* * *} p<.001$

\section{Discussion}

The aim of the study was to explore the direct and indirect (through school belonging) pathways from perceived social and academic competence to various indicators of well-being among students shortly after the transition to high school. We tested whether school belonging mediates the relationship between self-perception and well-being indicators concurrently and prospectively six months later.

The school belonging turned out to be an important mechanism linking perceived selfcompetence and well-being indicators. School belonging mediated the relationship between academic competence and well-being indicators at Time 1. After accounting for school belonging, relationships of academic competence and connectedness, optimism and happiness decreased substantially and became nonsignificant (except for optimism). The results suggested that perceived higher cognitive competence applied in schoolwork is associated with higher belonging to school, which in turn leads to greater general sense of connectedness, optimism and happiness in adolescents. Our results are similar to Phan et al. (2016), who documented the mediational role of engagement in the relationship between academic self-efficacy and well-being at school. Our research extends previous findings, suggesting that school belonging could be a link between academic competence and psychological adjustment of adolescents in non-educational settings. However, it should be mentioned that the mediational effect accounted only for $5-13 \%$ of connectedness variance (Fairchild, MacKinnon, Taborga, \& Taylor, 2009).

School belonging did not mediate the relationship between academic competence and engagement and perseverance, respectively. When controlling for school belonging, academic competence directly predicted students' engagement, perseverance and optimism at Time 1. The results suggest that perceived higher intelligence and cognitive abilities are directly related to higher engagement and perseverance, independent of the sense of school belonging. Our findings indicate that to promote student engagement and perseverance, cognitive resources, particularly perception of academic competence, should be emphasized. These findings correspond with the previous research of Mih and Mih (2013) documenting positive relationships between academic self-concept and engagement in learning, persistence in difficult tasks and enjoyment of academic work. Similarly, Phan et al. (2016) determined that academic self-efficacy positively influenced academic 
engagement in secondary school students. Our results add to previous research documenting direct concurrent association of academic competence to engagement, perseverance and optimism in a non-learning context. However, our results also suggested that a significant association between academic competence and engagement, perseverance and optimism exists in young people only concurrently. The positive effect of perceived academic competence shortly after the transition (directly or through school belonging) diminishes over time.

School belonging mediated relationships between perceived social competence and wellbeing indicators at Time 1 . The results suggested that higher perceived competence applied in social context enhance the students' sense of belonging to school, which in turn heightens their general capacity for optimism, connectedness and happiness. The effect size of mediation suggested that considerable amount of variance in optimism/connectedness/ happiness was attributable to the indirect effect (Fairchild et al., 2009), suggesting that school belonging in the transition period plays a crucial role in promoting adolescent positive functioning, concurrently. Similar patterns were found in prospective relationships with wellbeing indicators six months later. School belonging fully mediated (except for connectedness) the relation between social competence and optimism, connectedness and happiness. Our results suggest that students who perceive themselves as socially competent shortly after the transition tend to feel greater attachment to school and school members. This in turn may support later development of relatedness to other people, hopefulness and positive emotions in general. These results are in accordance with findings of Lester et al. (2013), who confirmed significant links between school belongingness measured at the beginning of the year with decreased depression at the end of the school year. Confirming the Stage-Envi- ronment Fit Theory (Eccles et al., 1993) and Expectancy Value Theory (Eccles \& Wigfield, 1995), findings indicate that the experience of acceptance and support in the context of school, as a result of an individual's perception of competence, may lead to further enhancing of adolescents' general capacity to connect to other people, to be optimistic and happy, regardless of the context.

In contrast to academic competence, social competence was directly related to optimism, happiness, and later connectedness, but not to engagement and perseverance. Our results are in line with previous research documenting stronger associations between social competence and psychological adjustment, whereas academic competence is more saliently related to achievement related outcomes (Kern et al., 2016; Olsson et al., 2012; Phan et al., 2016). Engagement and perseverance are connected with individual ability and strength and are thus more reflected in perceived academic competence. Social competence is applied in interpersonal context and thus promotes sense of connectedness and feelings of happiness.

However, it should be mentioned that association between academic and social competence and indicators of well-being was confirmed only concurrently and the relation decreased substantially after controlling for school belonging. The results suggested that, to enhance student's optimism, connectedness and happiness, developing students' cognitive resources might not be a sufficient condition. Moreover, as the tested prospective relations have suggested, to foster happy students with an optimistic view and positive relationships with others, intervention efforts should focus on individual feelings of school belonging during the transition period. Our findings confirm the belongingness hypothesis (Baumeister \& Leary, 1995), stating that although attachments to parents and positive relationships with friends are important for an individual's adjust- 
ment, those who do not have a sense of connection to a larger group or community will likely experience increased stress and emotional distress. For adolescents, school is the first source of experience of connection to a larger group. Our results indicate that a developed sense of connection to school in the period of transition may promote later overall well-being in adolescents, especially socially grounded indicators of youth well-being. Therefore, the transition to high school is an important period for enhancing youth mental health by providing social and contextual support (Lester et al., 2013).

The present study has several limitations. First, only self-report questionnaires were utilized. Results can be biased by self-evaluation of the students. Secondly, the sample consisted of students from high schools in one Slovak city, which limits generalizability of the results to other types of high schools and regions. Thirdly, we examined the level of self-perception and school belonging at only one time point, which did not allow us to test changes in cognitive and social factors and their predictive effect on students' well-being. However, our research enables us to identify crucial factors, acting in the transition period, that predict actual and prospective students' well-being. Moreover, other research has suggested that school belonging across the course of high school remains remarkably stable (O'Neel \& Fuligni, 2013) and its level in the beginning of the freshmen year has strong causal path leading to students' mental health in the following years (Lester et al., 2013).

Fourth, prospective relations were examined only over a six-month period using 109 respondents. The students that were absent and students lost to follow-up in the second measurement (approximately $21 \%$ of the initial sample) may have biased the results. A further longitudinal study should test respondents repeatedly during a longer period. A longitudinal study could also determine causal direction between study variables, which cannot be clearly addressed by the present study. For example, based on correlational analysis, it is unclear whether higher academic and social competence leads to better school belonging or stronger sense of school belonging leads to more positive perceptions of one's learning skills and interpersonal competence at school (Pittman \& Richmond, 2007).

Fifth, despite the fact that there were no significant gender differences in the studied variables, it would be plausible to test whether the direct and indirect effect of self-competence on well-being indicators might be moderated by gender. As the present study is a part of a larger longitudinal project and the article has limited length, we aim to test whether school belonging may function differently for male than female students and younger adolescents in further research. Finally, future research should examine several domains of connectedness and other individual characteristics (e.g., self-esteem, self-efficacy, motivation) in the prediction of adolescent positive functioning.

Despite the limitation, the strength of the present study is in examining multiple factors, acting during the transition period, that can promote indicators of adolescent well-being, concurrently and prospectively six months later. So far, only a small number of studies have investigated direct and indirect effects of school-related cognitive factors (both academic and social self-competence) through social sources on positive indicators of youth development in other than the academic domain. The implication of our findings is that context unspecified optimism, connectedness and happiness may be improved indirectly and prospectively (at least six months later) by fostering positive relations and emotions within the school. Satisfying developmental need for relatedness in the context of transitioning to high school, as a result of positive self-perception, seems to provide adolescents with a substantial basis for 
feeling positive about themselves, their future and other people. In contrast, students' individual ability to persevere and to be engaged in life tasks can be directly promoted by emphasizing their cognitive resources, particularly their academic competence as perceived shortly after the transition to high school.

\section{References}

Allen, K., Kern, M., Vella-Brodrick, D., Hattie, J., \& Waters L. (2016). What schools need to know about fostering school belonging: A meta-analysis. Educational Psychology Review, 1-34.

Antonovsky, A. (1993). The structure and properties of the Sense of Coherence Scale. Social Science and Medicine, 36(6), 725-733.

Babinčák, P., Mikulášková, G., \& Kovalčíková, I. (2012). Reliabilita, faktorová štruktúra a konštruktová validita Hartrovej metodiky self-perception profile for children. Československá Psychologie, 56(5), 448-446.

Baumeister, R. F., \& Leary, M. R. (1995). The need to belong: Desire for interpersonal attachments as a fundamental human motivation. Psychological Bulletin, 117, 497-529.

Blatný, M., \& Šolcová, I. (2016). Osobnostní předpoklady osobní pohody. Československá Psychologie, $60(1), 2-12$

Cohen, J. (1992). A Power Primer. Psychological Bulletin, 112(1), 155-159.

Danielsen, A. G., Samdal, O., Hetland, J., \& Wold, B. (2009). School-related social support and students' perceived life satisfaction. The Journal of Educational Research, 102(4), 303-318.

Deci, E. L., \& Ryan, R. M. (2000). The 'What' and 'Why' of goal pursuits: Human needs and the selfdetermination of behavior. Psychological Inquiry, 11, 227-268.

Eccles, J. S., Midgley, C., Wigfield, A., Buchanan, D. R., Flanagan, C., \& MacIver, D. (1993). Development during adolescence: The impact of stage/environment fit. American Psychologist, 48(2), 90-101.

Eccles, J. S., \& Wigfield, A. (1995). In the mind of the actor: The structure of adolescents' achievement task values and expectancy-related beliefs. Personality and Social Psychology Bulletin, 21(3), 215225 .

Fairchild, A. J., MacKinnon, D. P., Taborga, M. P., \& Taylor, A. B. (2009). R ${ }^{2}$ effect-size measures for mediation analysis. Behavior Research Methods, 41(2), 486-498.
Friedman, H. S., \& Kern, M. L. (2010). Personality: Contributions to health psychology. In J. M. Suls, K. W. Davidson, \& R. M. Kaplan (Eds.), Handbook of health psychology and behavioral medicine (pp. 102-119). New York: Guildford Press.

Gajdošová, E. (2016). New tasks of school psychologist in context with positive psychology. In E. Gajdošová (Ed.), Škola v kontexte psychológie zdravia a pozitívnej psychológie (pp.172-180). Praha, Czech Republic: Wolters Kluwer.

Goodenow, C. (1993). The psychological sense of school membership among adolescents: Scale development and educational correlates. Psychology in the Schools, 30, 79-90.

Goodman, R. (1997). The Strengths and Difficulties Questionnaire: A research note. Journal of Child Psychology and Psychiatry, 38, 581-586.

Harter, S. (2012). Self-perception profile for adolescents. USA, Denver: University of Denver.

Jose, P. E., Ryan, N., \& Pryor J. (2012). Does social connectedness promote a greater sense of well-being in adolescence over time? Journal of Research on Adolescence, 22(2), 235-251.

Kern, M. L., Benson, L., Steinberg, E. A., \& Steinberg, L. (2016). The EPOCH Measure of Adolescent Well-Being. Psychological Assessment, 28(5), 586597.

Lester, L., Waters, S., \& Cross, D. (2013). The relationship between school connectedness and mental health during the transition to secondary school: A path analysis. Journal of Psychologists and Counsellors in Schools, 23(2), 151-171.

Malecki, C. K., \& Elliott, S. N. (2002). Children's social behaviours as predictors of academic achievement: A longitudinal analysis. School Psychology Quarterly, 17, 1-23.

Maslow, A. (2014). O psychologii bytí. Praha: Portál.

Mih, V., \& Mih, C. (2013). Perceived autonomy-supportive teaching, academic self-perceptions and engagement in learning: Toward a process. model of academic achievement. An Interdisciplinary Journal, 18(4), 289-313.

OECD. PISA 2003. Student Questionnaire. OECD Publishing

O’Neel, C. G., \& Fuligni, A. J. (2013). A longitudinal study of school belonging and academic motivation across high school. Child Development, 84(2), 678692.

Olsson, C. A., McGee, R., Nada-Raja, S., \& Williams, S. M. (2013). A 32-year longitudinal study of child and adolescent pathways to well-being in adulthood. Journal of Happiness Studies, 14(3), 1069-1083.

Pečjak, S., \& Pirc, T. (2017). Bullying and perceived school climate: Victims' and bullies' perspective. Studia Psychologica, 59(1), 22-33. 
Phan, H. P., Hgu, B. H., \& Alrashidi, O. (2016). Role of student well-being: A study using structural equation modeling. Psychological Reports, 119(1), 77-105.

Pittman, L. D., \& Richmond, A. (2007). Academic and psychological functioning in late adolescence: The importance of school belonging. The Journal of Experimental Education, 75(4), 270-290.

Prokopčáková, A. (2015). Personal need for structure, anxiety, self-efficacy and optimism. Studia Psychologica, 57(2), 147-162.

Rodríguez-Fernández, A., Ramos-Díaz, E., FernándezZabala, A., Goni, E., Esnaola, I., \& Goni, A. (2016). Contextual and psychological variables in a Descriptive Model of Subjective Well-Being and School Engagement. International Journal of Clinical and Health Psychology, 16, 166-174.

Ronen, T., Hamama, L., Rosenbaum, M., \& MishelyYarlap, A. (2014). Subjective well-being in adolescence: The role of self-control, social support, age, gender, and familiar crisis. Journal of Happiness Studies, 15, 1-24.
Ryff, C. (1989). Happiness is everything or is it? Explorations on the meaning of psychological wellbeing. Journal of Personality and Social Psychology, 57, 1069-1081.

Seligman, M. (2014). Vzkvétaní. Nové poznatky o podstatě štstí a duševní pohody. Praha: Jan Melvil Publishing.

Tabachnick, B. G., \& Fidell, L. S. (2001). Using Multivariate Statistics. Boston: Allyn and Bacon. University Press.

Upadaya, K., \& Salmela-Aro, K. (2013). Development of school engagement in association with academic success and well-being in varying social contexts: A review of empirical research. European Psychologist, 18(2), 136-147.

Vaz, S., Falkmer, M., Ciccarelli, M., Passmore, A., Parsons, R., Tan, T., \& Falkmer, T. (2015) The personal and contextual contributors to school belongingness among primary school. Plos One, 10(4), 1-21. 